\title{
In situ Lu - Hf geochronology of garnet, apatite, and xenotime by LA ICP MS/MS
}

\author{
ALEXANDER SIMPSON ${ }^{1}$, SARAH GILBERT ${ }^{1}$, RENÉE \\ TAMBLYN $^{1}$, MARTIN HAND ${ }^{1}$, CARL SPANDLER $^{1}$, JACK \\ GILLESPIE $^{2}$, ANGUS NIXON ${ }^{1}$ AND STIJN GLORIE ${ }^{1}$ \\ ${ }^{1}$ The University of Adelaide \\ ${ }^{2}$ Curtin University
}

Presenting Author: a1193000@student.adelaide.edu.au

Lu-Hf geochronology is a powerful method to constrain the temporal evolution of geological systems. Traditional application of this dating method requires time consuming chemical separation of the parent $\left({ }^{176} \mathrm{Lu}\right)$ and daughter $\left({ }^{176} \mathrm{Hf}\right)$ isotopes that is commonly accompanied by loss of textural context of the analysed minerals. In contrast, In-situ (laser-ablation based) LuHf geochronology offers a number of advantages including rapid analysis with high spatial resolution, as well as control on textural relationships of the analysed mineral. However, laserablation based Lu-Hf geochronology has been hindered by isobaric interferences that have effectively masked reliable determination of ${ }^{176} \mathrm{Lu}$ and ${ }^{176} \mathrm{Hf}$. We present a methodology that resolves these interferences using laser ablation tandem inductively coupled mass spectrometry (LA-ICP-MS/MS) and $\mathrm{NH}_{3}$ gas to separate $\mathrm{Hf}$ from $\mathrm{Lu}$. Both $\mathrm{Lu}$ and $\mathrm{Hf}$ react with $\mathrm{NH}_{3}$ to form a variety of product ions. By measuring high order reaction products, we demonstrate that ${ }^{176} \mathrm{Hf}$ can be measured interference-free from both ${ }^{176} \mathrm{Lu}$ and ${ }^{176} \mathrm{Yb}$ with sufficient sensitivity to yield useful geochronological age data.

The novel in-situ Lu-Hf technique has been successfully applied to a variety of Palaeozoic and Precambrian-aged garnet, apatite and xenotime samples, including published reference materials. The resulting age uncertainties are as low as $\sim 0.5 \%$ ( $95 \%$ conf. interval). The technique has the potential to obtain spatially resolved Lu-Hf ages in garnet-bearing samples that would be difficult to obtain by conventional techniques. The method also offers the opportunity for rapid "campaign style" geochronology in complex terrains that record poly-metamorphic histories. For apatite, the probable higher closure temperature of the Lu-Hf system compared to the commonly used U-Pb system enhances the likelihood to obtain crystallization ages for metamorphosed and/or U-poor samples, as well as hightemperature thermal history reconstructions. Furthermore, given that apatite and xenotime are commonly associated with mineralizing fluids, the in-situ Lu-Hf method may become a valuable addition to the mineral exploration toolbox. 